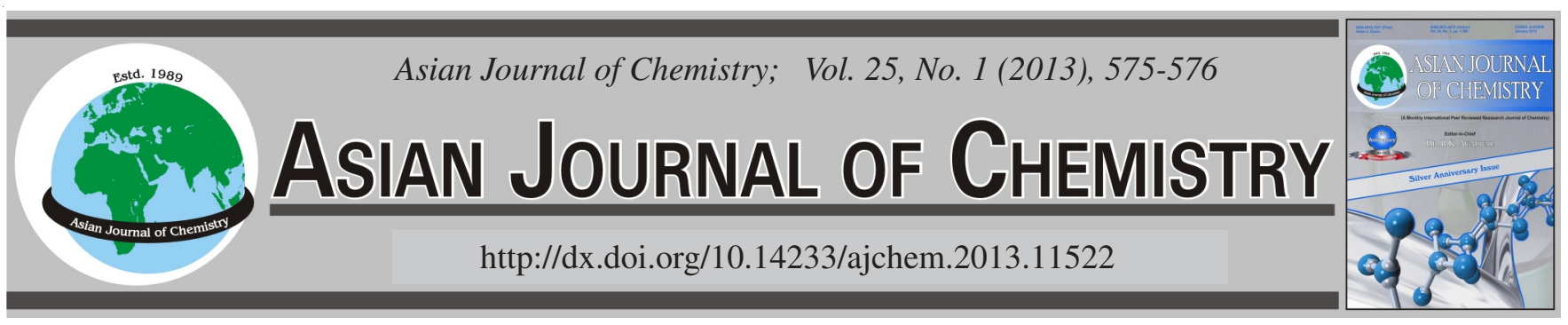

NOTE

\title{
Detection and Removal of Lead from the Local Industrial Wastewaters
}

\author{
Gugan JabeEn and Shazia Khurshid*
}

Department of Chemistry, Government College University, Lahore, Pakistan

*Corresponding author: E-mail: shezra_ahmed2000@yahoo.com

This work reported the removal of lead from the samples of effluents collected from a local industrial cluster by its adsorption on Nymphaea alba (nilofar flower). The estimation of lead in industrial effluents before and after adsorption was accomplished applying atomic absorption spectrometry.

Key Words: Lead, Adsorbent, Nymphaea alba (Nilofar flower), Wastewater.

Removal of lead from industrial wastewater like other toxic metals is need of today. Number of methods have been utilized for the removal of toxic metals from wastewaters. Several natural and cheap adsorbants viz., sea nodules ${ }^{1}$, aluminium-red mud $^{2}$, activated tea waste ${ }^{3}$, granulated blast furnace $\mathrm{slag}^{4}$, etc. have been used for the removal of heavy metal ions. Nymphaea alba (Nilofar) flower is easily available in Pakistan and used as an adsorbent for the removal of lead from industrial waste effluents.

Nymphaea alba was collected from different ponds. It was washed with double distilled water and dried in oven at $50^{\circ} \mathrm{C}$ for $1 \mathrm{~h}$. After complete dryness, it was powdered, sieved and stored.

Calibration curve for lead: Estimation of lead was done against standard lead acetate solutions. $2.8309 \mathrm{~g}$ of lead acetate was dissolved in $1 \mathrm{~L}$ of distilled water. Other standard solutions of required concentrations were prepared from stock solution. $50 \mathrm{~mL}$ of different ppm solutions were transferred to conical flasks. Absorbance was measured at $283.3 \mathrm{~nm}$ by using atomic absorption spectrometer, AA-100 Perkin Elmer. Calibration curve was plotted between absorbance and concentration of known standards. A correlation coefficient of 0.9584 was obtained for the calibration curve (Fig. 1).

Adsorption experiment: Adsorption experiment was done at room temperature after taking $50 \mathrm{~mL}$ of known concentration of lead solutions in different flasks. Different amount of adsorbent were added in each flasks and were shaken at $100 \mathrm{rpm}$ for $0.5 \mathrm{~h}$. All samples were treated in the same manner after that solutions were double filtered off. Analysis of solutions was done by atomic absorption spectrometer at

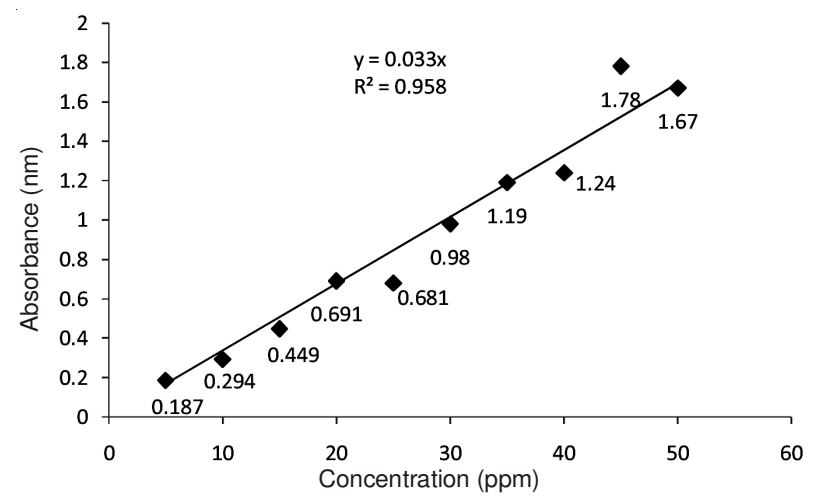

Fig. 1. Calibration curve for lead

$283.3 \mathrm{~nm}$. As the amount of adsorbent was varied, with that maximum adsorption of $89 \%$ was achieved with $0.6 \mathrm{~g}$ of adsorbent (Fig. 2).

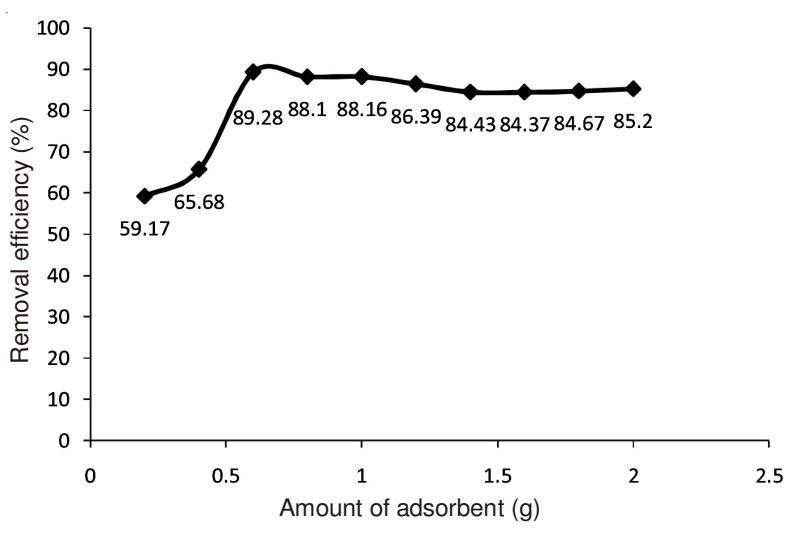

Fig. 2. Effect of the amount of adsorbent 
Effect of contact time: $50 \mathrm{~mL}$ of $50 \mathrm{ppm}$ concentration solutions were transferred to different flasks. Then $0.6 \mathrm{~g}$ of adsorbent was added each and shaken at $100 \mathrm{rpm}$ for different time intervals like 10, 20, 30, 40 ......100 min. After that solutions were doubly filtered off. The results revealed that more contact time proved better removal of metal from solution. When contact time was 100 min the maximum removal of $93 \%$ was observed (Fig. 3).

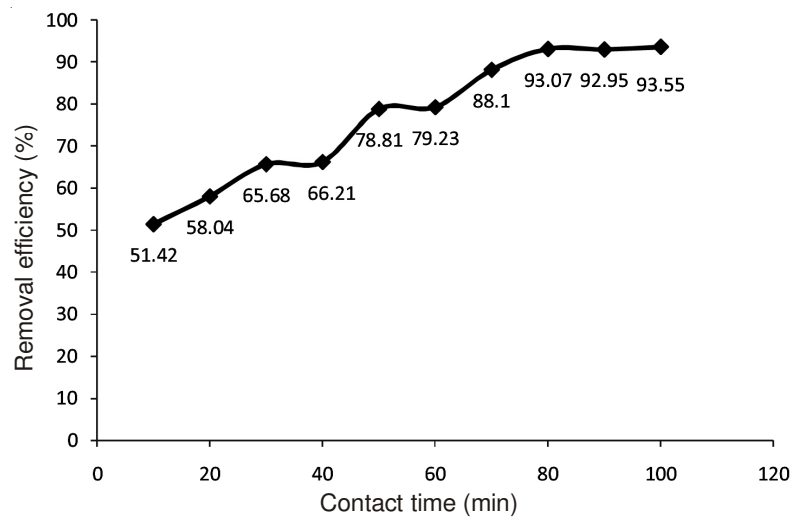

Fig. 3. Effect of contact time

Effect of thermal treatment: $50 \mathrm{~mL}$ of $50 \mathrm{ppm}$ solution was taken in different flasks. $0.6 \mathrm{~g}$ of adsorbent was added to each flask. These flasks were shaken in an incubator shaker at $100 \mathrm{rpm}$ for $100 \mathrm{~min}$ at different temperatures. The removal of metal from effluents was more efficient at high temperature. The maximum removal of $95 \%$ was observed at $60^{\circ} \mathrm{C}$ (Fig. 4).

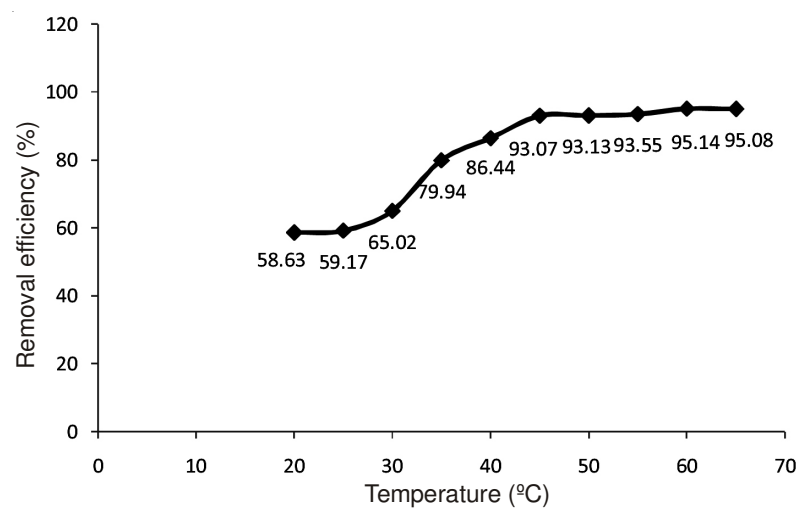

Fig. 4. Effect of temperature

Effect of pH: Standard solutions were taken in different flasks. Then $0.6 \mathrm{~g}$ of adsorbent in each flask were added after that different $\mathrm{pH}$ ranges like $2,3,4 \ldots . .11$ were adjusted with $0.1 \mathrm{M} \mathrm{NaOH}$ or $\mathrm{HCl}$ solution. These flasks were shaken in shaker at $100 \mathrm{rpm}$ for $100 \mathrm{~min}$ at $60^{\circ} \mathrm{C}$. Maximum absorbance of $92 \%$ was observed at pH 8 (Fig. 5).

Effect of agitation speed: To the standard solutions $0.6 \mathrm{~g}$ of adsorbent was added and $\mathrm{pH}$ was adjusted 8. These flasks were shaken in an incubator shaker at $60{ }^{\circ} \mathrm{C}$ for $100 \mathrm{~min}$ at different agitation speeds. Maximum removal was observed at maximum shaking. With maximum shaking adsorbent and metal get more surface area to come in contact and react fastly. So solution at agitation speed of $175 \mathrm{rpm}$ gave best adsorption of $93 \%$ than at low speed (Fig. 6).

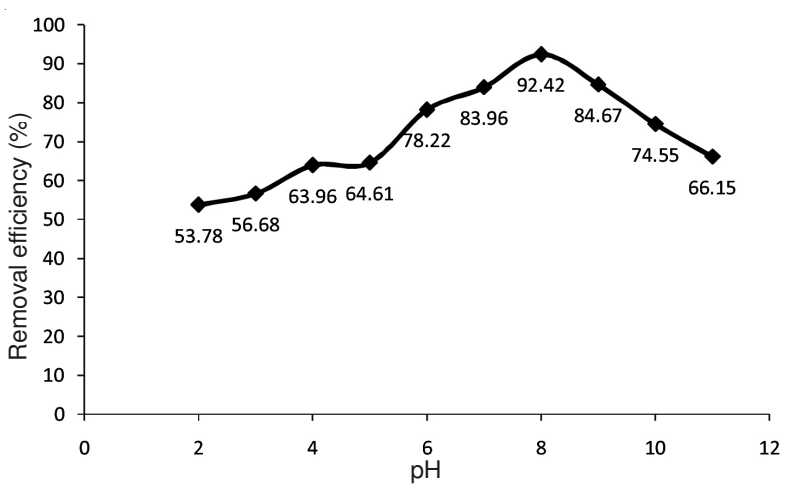

Fig. 5. Effect of $\mathrm{pH}$

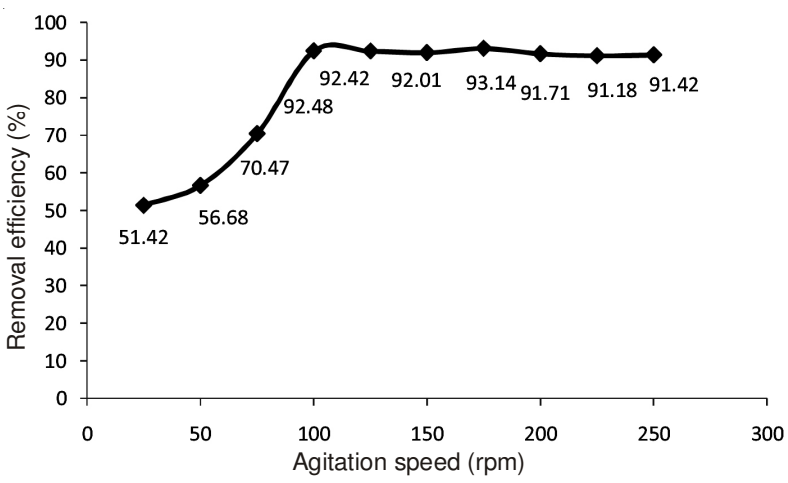

Fig. 6. Effect of agitation speed

Removal of lead from dying industry: Waste effluent collected from Hassan Dying industry near Sheikhpura was treated by using same method as used above for lead standard solutions. The results are found to be satisfactorily (Table-1).

\begin{tabular}{ccccc}
\multicolumn{5}{c}{ TABLE-1 } \\
REMOVAL OF LEAD FROM HASAN DYING INDUSTRY \\
\hline $\begin{array}{c}\text { Initial } \\
\text { concentration of } \\
50 \text { mL of solution } \\
(\mathrm{ppm})\end{array}$ & $\begin{array}{c}\text { Mass } \\
\text { adsorbent } \\
(\mathrm{g})\end{array}$ & $\begin{array}{c}\text { Absorbance } \\
\text { after } \\
\text { removal } \\
(\mathrm{nm})\end{array}$ & $\begin{array}{c}\text { Concentration } \\
\text { after removal } \\
(\mathrm{ppm})\end{array}$ & $\begin{array}{c}\text { Removal } \\
\text { efficiency } \\
(\%)\end{array}$ \\
\hline 48.90 & 0.2 & 0.711 & 21.03 & 56.98 \\
48.90 & 0.6 & 0.163 & 4.822 & 90.13 \\
48.90 & 1.0 & 0.286 & 8.46 & 82.69 \\
48.90 & 1.6 & 0.216 & 6.39 & 86.93 \\
48.90 & 2.0 & 0.408 & 12.07 & 75.31 \\
\hline
\end{tabular}

\section{REFERENCES}

1. B.M.W.P.K. Amarasinghe and R.A. Williams, Chem. Eng. J., 132, 299 (2007).

2. H. Benhima, M. Chiban, F. Sinan, P. Seta and M. Persin, Colloids Surf. B, 61, 10 (2008).

3. S. Bhattacharjee, S. Chakrabarty, S. Maity, S. Kar, P. Thakur and G. Bhattacharyya, Water Res., 37, 3954 (2003).

4. S.V. Dimitrova and D.R. Mehandgiev, Water Res., 32, 3289 (1998). 